\title{
FINITE ELEMENT ANALYSIS OF THERMOMECHANICAL BEHAVIOUR OF POWDERS DURING TABLETTING
}

\author{
Alexander Krok ${ }^{1}$, Pablo García-Triñanes ${ }^{1}$, Marian Peciar $^{2}$, Chuan-Yu Wu ${ }^{1}$ \\ 1 Department of Chemical and Process Engineering, University of Surrey, Guildford, \\ GU2 7XH, UK \\ 2 Department of Chemical and Hydraulic Machines and Equipment, Slovak University of \\ Technology, Bratislava, 812 31, Slovakia \\ Email: a.krok@surrey.ac.uk
}

\begin{abstract}
In the current paper, a systematic finite element (FE) analysis of the thermo-mechanical behaviour of pharmaceutical powders during die compaction is performed using the FE solver ABAQUS. The transformation of irreversible compression work to heat during compaction is considered, so is the energy dissipated by the particle-particle friction, and die-wall friction. Die compaction with various shaped punches to produce flat-face (FF), shallow convex (SC) and standard convex (STC) tablets at different compression speeds are then analysed. Evolutions of density and temperature distributions during compaction are examined. The effect of die wall friction on thermo-mechanical behaviours is also explored. It is shown that the punch shape, the compression speed and die-wall friction significantly affect the thermomechanical behaviour. The maximum temperature and temperature distribution of the compressed powder changes dramatically when different shaped punches are used. The maximum temperature of the tablet upon ejection can be reduced by decreasing the die-wall friction or the compression speed.
\end{abstract}

\section{KEYWORDS}

Die compaction, Finite element analysis, Thermomechanical modelling, Wall friction, Tabletting, Temperature.

\section{INTRODUCTION}

Die compaction is a process widely used to manufacture high quality particulate products (e.g. products made of powders or granules), such as pharmaceutical and detergent tablets, and metallic and ceramic parts (Wu, Ruddy, Bentham, Hancock, Best \& Elliott, 2005, Sinka \& Cocks, 2008, Wu, Hung, Miquélez-Morán, Gururajan \& Seville, 2010), during which powders are compressed under high pressures to produce coherent compacts. Appropriate process conditions need to be chosen in order to minimise any density variation, build-up of intensive shearing and residual stresses in the compacts and occurrence of defects (e.g. capping and lamination). Many studies were hence devoted to mechanistic understanding of compression behaviour, in particular, the failure mechanisms during die compaction (Diarra, 
Mazel, Busignies \& Tchoreloff, 2013; Kadiri \& Michrafy, 2013; Muliadi, Litster \& Wassgren, 2013).

During die compaction, heat can be induced by interparticle (particle-particle) and particlewall friction, and irreversible deformation of particles that leads to the conversion of some mechanical energy to heat (Cespi, Bonacucina, Casettari, Ronchi \& Palmieri, 2013). Consequently, the temperature of the powder mass will increase, as reported by Hanus \& King (1968), Ketolainen, Ilkka \& Paronen (1993), and Travers \& Merriman (1970). Hanus et. al., (1968) investigated the effects of compression speed and pressure on the change of powder temperature during compression. Calcium carbonate and sodium chloride were examined, and thermometric measurements were performed. They showed that the rise in temperature during compression of sodium chloride could be as high as $30^{\circ} \mathrm{C}$ and for calcium carbonate as high as $40^{\circ} \mathrm{C}$. However, the rise of temperature in ejected tablets was far less. This implied that some generated heat during compression might be dissipated. The temperature rise during compaction of asagran, sodium chloride and boric acid was examined by Travers et al. (1970), who measured the temperature using thermocouple and found that for all materials considered the temperature increased during compression but decreased during decompression and ejection. The effects of compression forces, compression speed and lubrication on the temperature change were also investigated by Bechard \& Down (1992), who compressed a mixture of $35 \%$ microcrystalline cellulose (MCC, Avicel PH 102) and $65 \%$ spray-dried lactose DCL11 in a rotary tableting machine with deep concave tools, and used magnesium stearate as the internal lubricant. They showed that infrared imaging is a unique tool for monitoring infrared radiation evolved after compaction with good reproducibility and accuracy, and the temperature of tablets increased as the compression force and the compression speed increased. In addition, the compression speed was found to have a greater influence on the tablet temperature than the compression force (see also Nürnberg \& Hopp, 1981). It is also well recognised that the die-wall friction can have a significant effect on the temperature change during compaction, as with increasing the amount of lubricant (i.e. a decrease in friction) the temperature of tablets decreased (Hanus et al., 1968; Bechard et al., 1992; Michrafy, Hass, Kadiri, Sommer \& Dodds, 2005).

The temperature rise in powders can affect their mechanical behaviour. For example, Michrafy et al. (2005) investigated powder compaction at different temperatures using a modified hydraulic press with an environment chamber heated with hot air. The temperature 
in the chamber was controlled using a control unit and measured with a thermal sensor. They showed that the ratio of radial stress to axial stress and the die-wall friction increased as the temperature increased. The increase in temperature during die compaction can also influence powder compressibility and tablet strength. Roue`che, Serris, Thomas \& Périer-Camby (2006) developed a thermo-regulated die and performed uniaxial compaction at various temperatures. It was shown that tablets with different microstructures (e.g. porosity) and mechanical behaviours (e.g. tensile strength) were obtained. In the temperature range (i.e. below $80^{\circ} \mathrm{C}$ ) considered, the tablet porosity was not significantly affected by temperature, but tensile strength was significantly increased with the increasing temperature. The temperature rise can also affect physiochemical properties of the medicinal substances, including chemical stability, crystallinity and polymorphous state (Zhang, Law, Schmitt \& Qiu, 2004). The temperature increase in the powder during compaction is hence detrimental to heat sensitive materials with low heat conductivity, such as most organic materials used in pharmaceutical formulations.

Therefore, it is important to understand the thermo-mechanical behaviour of powders during compaction. A coupled mechanical and thermal analysis of powder compaction was performed using the finite element method (FEM) by Zavaliangos, Galen, Cunningham \& Winstead (2007), who examined the evolution of the temperature distribution when a microcrystalline cellulose (MCC) powder (grade Avicel PH102) was compressed with flatfaced punches to make flat-faced tablets. The temperature variation on the surface of the tablet was also experimentally measured using an infrared thermoviewer, in order to validate the numerical analysis. They found that, at low compression speeds, the temperature at the tablet surface monotonically decreased towards the edges in the radial direction. At high compression speeds, the temperature slightly increased toward the edges in the radial direction (i.e. the temperature near the edges was slightly higher than that in the centre), which was attributed to the heat generated due to the die wall friction at the powder -wall interface. Klinzing, Zavaliangos, Cunningham, Macaro \& Winstead (2010) examined the temperature distribution in capsule-shaped tablets made of MCC PH102 using FEM and IR thermography. They found that the temperature distributions obtained from the numerical simulations were consistent with the experimental measurements. These demonstrated that FEM was a very useful tool for analysing the thermo-mechanical behaviour of powders during compaction. 
Nevertheless, previous studies mainly focused on the thermo-mechanical behaviour of powders during die compaction with flat-face punches. As most pharmaceutical tablets have a convex surface, it is hence of interest to explore whether the thermo-mechanical behaviour is influenced by punch shapes. Therefore, the objective of this study was to explore the effect of punch shape on thermo-mechanical behaviour of powders during compaction. A systematic numerical study was hence performed using FEM, and die compaction with various punch shapes; flat-face (FF), shallow convex (SC) and normal convex (NC), at different compression speeds with various die wall friction were analysed.

\section{THE NUMERICAL METHOD}

A proper description of the mechanical and thermal response of powders during compaction requires appropriate constitutive models. Treating powders as continuum elastic-plastic materials, a widely used constitutive model for analysing the mechanical behaviour of powders is the Drucker Prager Cap (DPC) model. The DPC model assumes that the behaviour of the material is isotropic and the yield surface is composed of three segments (Wu et al. 2005; Han, Elliott, Bentham, Mills, Amidon \& Hancock, 2008; Sinha, Bharadwaj, Curtis, Hancock \& Wassgren, 2010; Krok, Peciar \& Fekete, 2014):

i) A Mohr-Coulomb shear failure surface representing the shear flow behaviour. It is defined by cohesion $(d)$ and the internal friction angle $(\beta)$. Introducing the hydrostatic stress, $p=\frac{1}{3} \operatorname{trace}(\boldsymbol{\sigma})$ and the Mises equivalent stress $q=\sqrt{\frac{3}{2}(\mathbf{S}: \mathbf{S})}$ (S is the tensor of deviator stress defined as $\mathbf{S}=\boldsymbol{\sigma}+p \mathbf{I}$, while $\boldsymbol{\sigma}$ is the stress tensor and $\boldsymbol{I}$ is the identity matrix, and the compressive stresses are defined as positive), the shear failure surface is mathematically given as:

$$
F_{s}(p, q)=q-d-p \tan (\beta)=0
$$

Graphically, in the p-q plane, $d$ is the intersection of the shear failure surface with the $q$ axis, while $\beta$ is the slope of the shear failure surface. As shown in Procopio, Zavaliangos \& Cunningham, Sinka \& Zavaliangos (2003), Brewin, Coube, Doremus \& Tweed (2008), Han et al. (2008) and Krok et al. (2014), cohesion $(d)$ and the internal friction angle $(\beta)$, can be determined using diametrical and unconfined uniaxial compression tests. 
ii) A cap surface describing plastic yield, which is defined as:

$$
F_{c}(p, q)=\sqrt{\left(p-p_{a}\right)^{2}+\left(\frac{R_{E} q}{1+\alpha-\alpha / \cos (\beta)}\right)^{2}}-R_{E}\left(d+p_{a} \tan (\beta)\right)=0
$$

where $R_{E}$ and $p_{a}$ are the cap eccentricity and the evolution parameter, respectively, which can be determined from uniaxial compression using a die instrumented with sensors to measure the radial stresses (Cunningham, Sinka \& Zavaliangos, 2004; Han et al., 2008; Krok et al., 2014).

and iii) A transition surface, which is introduced to ensure the numerical stability by creating a smooth transition between the shear failure surface and the cap surface and is defined as:

$F_{t}(p, q)=\sqrt{\left(p-p_{a}\right)^{2}+\left[q-\left(1-\frac{\alpha}{\cos (\beta)}\left(d+p_{a} \tan (\beta)\right)\right)\right]^{2}}-\alpha\left(d+p_{a} \tan (\beta)\right)=0$

where $\alpha$ is a constant defining the size of the transition segments and generally has a small number between 0.01-0.05.

An associated plastic flow is assumed for the cap surface, while a nonassociated plastic flow for the shear failure surface and the transition surface are used. These plastic flow rules determine the directions of the plastic strain. The cap hardening/softening law $p_{b}=f\left(\varepsilon_{v}\right)$ represents the hardening driven by the volumetric plastic strain $\left(\varepsilon_{v}\right)$ and is given as:

$$
p_{b}=p_{a}+R_{E}\left(d+p_{a} \tan (\beta)\right)
$$

The volumetric plastic strain $\varepsilon_{\mathrm{v}}$ is defined as $\varepsilon_{v}=\ln \left(\frac{R D}{R D_{0}}\right)$, where $R D$ and $R D_{0}$ are the current relative density of the compacted powder and the initial relative density of loose powder, respectively (Han et al., 2008; Muliadi et al., 2013; Krok et al., 2014; Mazor, Perez-Gandarillas, Ryck \& Michrafy, 2016). 
To model the thermo-mechanical behaviour during powder compaction, it is assumed that the heat transfer in the powder is dominated by conduction. Heat transfer due to convection and radiation is ignored in this study. Three primary factors contributing to the change in temperature within the powder are considered: (i) friction between particles; (ii) die-wall friction along the tooling surfaces; and (iii) plastic deformation of the particles. The temperature gradient throughout the powder can be described using the Fourier-Kirchhoff differential equation:

$$
\rho C_{p} \frac{d T}{d t}=\nabla(k \nabla T)+\dot{q}_{p}
$$

where $\rho\left(\mathrm{kg} \cdot \mathrm{m}^{-3}\right), C_{p}\left(\mathrm{~J} \mathrm{~kg}^{-1} \mathrm{~K}^{-1}\right), T(\mathrm{~K})$ and $k\left(\mathrm{~W} \mathrm{~m}^{-1} \mathrm{~K}^{-1}\right)$ are the local density, specific heat, temperature and thermal conductivity, respectively. $\dot{q}_{p}$ represents the total heat source generated in the powder and is primarily composed of two terms, i.e.

$$
\dot{q}_{p}=\dot{q}_{\phi}+\dot{q}_{\omega}
$$

where $\dot{q}_{\phi}$ is the amount of heat generated from inter-particle friction and plastic deformation of the particles during compaction and is related to the stresses and strains of the material (Rahman, Ariffin \& Nor, 2009):

$$
\dot{q}_{\phi}=\xi \sum_{i, j=1}^{3} \sigma_{i j} d \varepsilon_{i j}^{p l}
$$

where $\xi(-)$ represents an inelastic heat fraction. It is fraction of inelastic dissipation rate that appears as a heat flux per unit volume source in a fully coupled thermal-stress analysis. $\dot{q}_{\omega}$ in Eq. (8) denotes the heat generated as a result of wall friction, i.e. the amount of heat generated from the interaction between the powder and the die wall, and can be given as (Zavaliangos et. al., 2007)

$$
\dot{q}_{\omega}=\int_{A} v \mu \sigma_{n n} d A
$$


It depends on the wall friction coefficient $\mu(-)$, the interacting area $A\left(\mathrm{~m}^{2}\right)$ between the powder and the die wall, the local normal stress $\sigma_{\mathrm{nn}}(\mathrm{Pa})$ and the norm of the local slip velocity at the interface between the powder and the die $v\left(\mathrm{~m} \mathrm{~s}^{-1}\right)$.

It is evident that part of the heat $\dot{q}_{\omega}$ generated at the frictional interface will flow to the powder and also to the die tools. While, the heat $\dot{q}_{I}$ as a result of wall friction dissipated to powder is given by the Eq. (9) and the heat $\dot{q}_{I I}$ which dissipated to the die is given by Eq. (10):

$$
\begin{aligned}
& \dot{q}_{I}=(1-\eta) \dot{q}_{\omega} \\
& \dot{q}_{I I}=\eta \dot{q}_{\omega}
\end{aligned}
$$

where $\eta$ represents a weighting factor. This parameter indicates the fraction of heat that passes, into each side of the contact pair. The weighting factor $\eta$ can be estimated (Reznikov, 1981; Grzesik, 2008) using the Eq. (11):

$$
\eta=\frac{1}{1+\left(\frac{3 k_{I}}{2 k_{I I}}\right) \sqrt{\frac{\lambda_{I I}}{\lambda_{I}}}}
$$

where $k_{I}, k_{I I}, \lambda_{I}, \lambda_{I I}$ are thermal conductivity of the powder, thermal conductivity of the die tools, thermal diffusivity of the powder and thermal diffusivity of the die tools, respectively. Afterward, the thermal diffusivity $\lambda$ can be calculated using Eq. (12).

$$
\lambda=\frac{k}{\rho C_{p}}
$$

\section{THE FINITE ELEMENT MODEL}

In the current study, a commercial FEM software, ABAQUS/Standard, was used, in which the DPC model was implemented. This is the same FE solver as that Zavaliangos et al. (2007) used. In contrast to the study of Zavaliangos et al. (2007) that used constant thermal properties, the dependence of thermal properties on the relative density was considered in this 
study. In order to calculate the relative density of powder during compaction, a user-defined subroutine USDFLD was developed. Powder compaction processes were then treated as a coupled temp-displacement (transient) problem.

Microcrystalline cellulose (MCC) of the grade Avicel PH 102 was used as the model material. The same material properties as that reported in Krok et al. (2014) were used, in which the transition coefficient was arbitrarily set as $\alpha=0.01$, but a sensitivity analysis using the values in the recommended range $(0.01 \sim 0.05)$ showed that the variation in the transition coefficient has only a very small effect on the compaction behaviour. For example, when the transition coefficient increased from 0.01 to 0.05 , the Mises equivalent stress decreased from $9.81 \mathrm{MPa}$ to $9.76 \mathrm{MPa}$, the equivalent hydrostatic pressure increased from $8.8 \mathrm{MPa}$ to $9.7 \mathrm{MPa}$, and the maximum temperature of the tablet after compression decreased from $40{ }^{\circ} \mathrm{C}$ to $38^{\circ} \mathrm{C}$. The bulk density of the loose powder was $335 \mathrm{~kg} / \mathrm{m}^{3}$, and the true density was $1,570 \mathrm{~kg} / \mathrm{m}^{3}$. The mechanical properties of the powder as a function of the relative density $(R D)$ were given as follows (Krok et al., 2014):

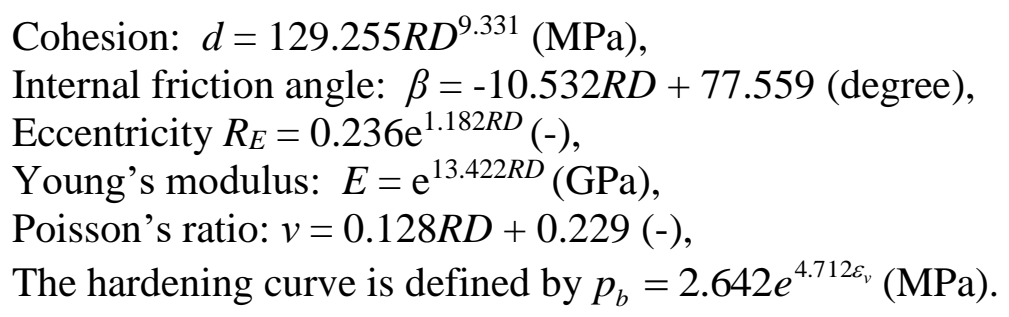

The thermal properties of the powder $\left(C_{p}\right.$ and $\left.k\right)$ were measured using a thermal conductivity analyser (TCA, C-Therm, UK). Using powder and tablets of different densities, the thermal properties were hence determined as a function of the relative density $(0.21 \leq R D \geq 0.785)$ as

Thermal conductivity: $k=0.1077 R D^{2}+0.1995 R D+0.0603\left(\mathrm{~W} \mathrm{~m}^{-1} \mathrm{~K}^{-1}\right)$, Specific heat: $C_{p}=3320.1 R D^{2}-5217.5 R D+2925.4\left(\mathrm{~J} \mathrm{~kg}^{-1} \mathrm{~K}^{-1}\right)$.

The thermal expansion coefficient $\alpha_{\mathrm{T}}=1.0 \times 10^{-4}\left[{ }^{\circ} \mathrm{C}^{-1}\right]$ reported by Zavaliangos et al. (2007) was used in this study. Since the fraction of irreversible work converted to heat was estimated to be in the range of $80-100 \%$ (Bever, Holt \& Titchener, 1973; Arruda, Boyce \& Jayachandran, 1995). It was assumed that $10 \%$ of the mechanical energy $(\xi=0.9)$ was stored as the permanent mechanical deformation energy inside the compressed powder, i.e. a large portion of the energy (90\%) was converted to heat. 
In fact that in ABAQUS/Standard is possible to set up a weighting factor $\eta$ only as a constant value; it was made an assumption that the heat conduction between the powder and the die is independent on the relative density of the powder.

For a known values of thermal conductivity $\left(k_{I I}=30 \mathrm{Wm}^{-1} \mathrm{~K}^{-1}\right)$ and specific heat $\left(C_{p, I I}=480\right.$ $\mathrm{Jkg}^{-1} \mathrm{~K}^{-1}$ ) of the tool steel (Kaschnitz, Hofer \& Funk, 2012) and exercise Eq. (12), the thermal diffusivity $\left(\lambda_{I I}=8.116^{*} 10^{-6} \mathrm{~m}^{2} \mathrm{~s}^{-1}\right)$ was calculated. At the same time, from measured values of thermal conductivity and specific heat of the powder $\left(k_{I}=0.292 \mathrm{Wm}^{-1} \mathrm{~K}^{-1} ; C_{p, I}\right.$ $\left.=875.6 \mathrm{Jkg}^{-1} \mathrm{~K}^{-1}\right)$ for the relative density $R D=0.785$, the thermal diffusivity $\left(\lambda_{I}=2.655^{*} 10^{-7}\right.$ $\mathrm{m}^{2} \mathrm{~s}^{-1}$ ) was adapt. Subsequently, it was estimated using Eq. (11) that up to $92 \%$ of the heat can be dissipated into the die tools.

The increase of temperature in the die is closely related to the final temperature of the tablet and the properties of the material can affect the final distribution of temperature. For compression speed $12 \mathrm{~mm} / \mathrm{s}$ and wall friction $\mu=0.3$ no changes in temperature in the die were observed (maximum temperature was $35^{\circ} \mathrm{C}$ after compression) and for compression speed $120 \mathrm{~mm} / \mathrm{s}$ and wall friction $\mu=0.5$, the temperature in the die only slightly increased (maximum temperature after compression was $40^{\circ} \mathrm{C}$ ).

Heat transfer between the die and the powder compact can be reasonably justified, especially in the case of the continuous production of tablets, where the temperatures of tablets and the die increase until steady state condition. While using modern tableting machines for continuous run for a certain period, the temperature of the die can be higher than the temperature of the tablet. In this case, the heat transfer between the die and the powder is critical for the prediction of the temperature distribution.

Cylindrical tablets with various surface curvatures, as shown in Figure 1, were modelled. All the tablets had a diameter of $8 \mathrm{~mm}$. For all cases considered, the powder had an initial maximum height of $6 \mathrm{~mm}$ (i.e. $\mathrm{H}=6 \mathrm{~mm}$ ). The upper and lower punches with different surface curvatures were modelled as rigid bodies. For making shallow convex tablets (Fig. 1b), the radius of the punch surface curvature was $13.5 \mathrm{~mm}$ and the punch depth was $0.58 \mathrm{~mm}$; for the standard convex tablets (Fig. 1c), the radius of the punch surface curvature was $8.5 \mathrm{~mm}$ and the punch depth was $0.85 \mathrm{~mm}$. As it is an axi-symmetrical problem, the powder was modelled as a $2 \mathrm{D}$ axisymmetric deformable continuum. The powder was discretised using a non- 
adaptive mesh composed of 7,700 CAX4T elements (a 4-node axisymmetric thermally coupled quadrilateral, bilinear displacement and temperature) with displacement - temperature degrees of freedom. The initial temperatures of the powder die and punches were set as $22^{\circ} \mathrm{C}$ (i.e. the ambient temperature). All three stages of a typical compaction process, i.e., compression, decompression and ejection, were modelled. The simulation was performed with controlled displacement of the upper punch and the compaction stage was terminated when the compressed tablet completely ejected from the die. The interaction between the powder and the tooling surfaces was modelled as master-slave contacts with finite sliding (using the "Coulomb friction model").

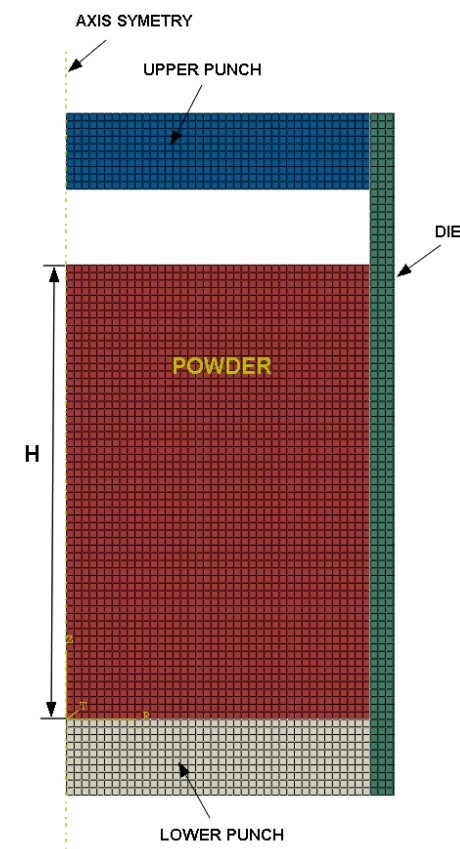

(a)

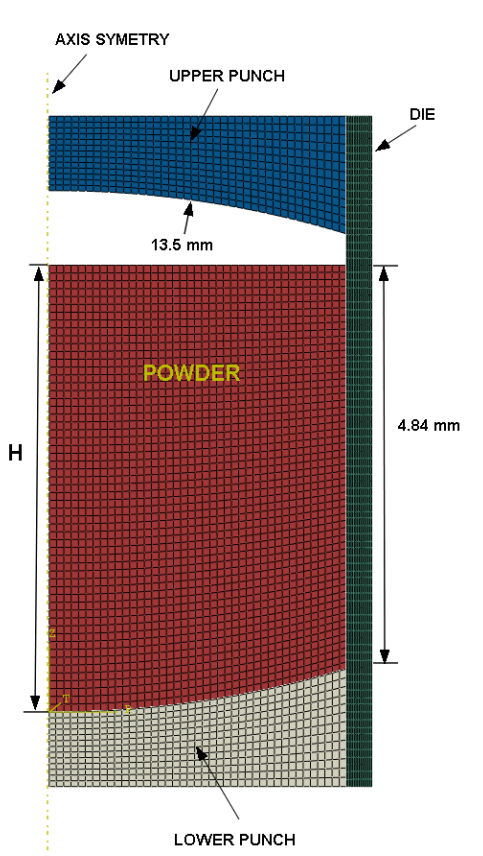

(b)

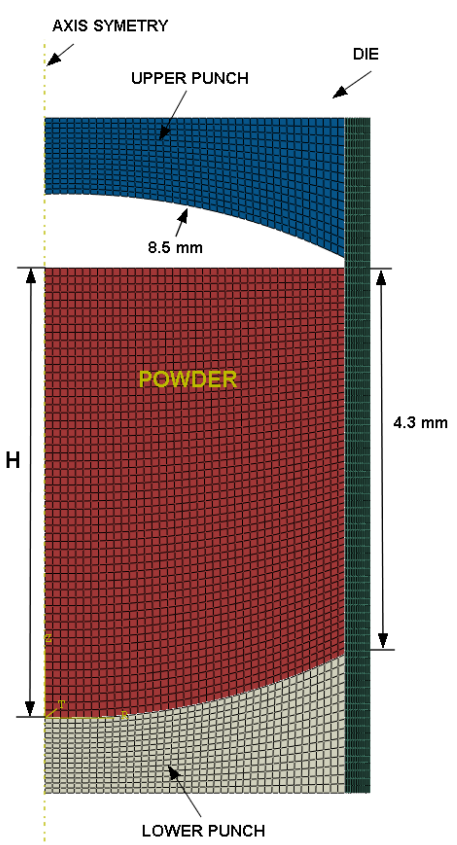

(c)

Figure 1 FEM models for making a) flat face (FF) tablets; b) shallow convex (SC) tablets; c) standard convex (STC) tablets.

\section{RESULTS AND DISCUSSION}

\subsection{TYPICAL THERMOMECHANICAL BEHAVIOUR DURING POWDER COMPACTON}

Figure 2 shows the typical evolution of the stress state at the point in the middle centre of powder in the $p-q$ plane during the powder compaction process using flat-faced punches, in which the calibrated DPC yield surface was also superimposed. The corresponding relative density distributions $(R D)$ at various time instants labelled in Figure 2 are shown in Figure 3. Point $A$ denotes the onset of compression process before the upper punch is in contact with the powder and at which the initial relative density is assumed to be uniformly distributed with a value of 0.21 . The powder is compressed until the stress state reaches Point $C$ with a 
minimum separation of $2 \mathrm{~mm}$ at the maximum compression pressure. Thereafter, unloading takes place and the values of $p$ and $q$ decrease. Point $D$ represents a critical instant during unloading, at which the axial stress is reduced to the same value as the radial stress, i.e. $q=0$. As the hydrostatic stress $p$ decreases further, the value of Mises equivalent stress $q$ starts to increase (Wu et al., 2005; Sinha et al. 2010). Point $E$ indicates the beginning of ejection while Point $F$ marks the completion of the ejection (see Fig. 3). The evolutions of the stress state and density distribution during compaction are in broad agreement with that reported in Wu et al. (2005), Sinka, Cunningham \& Zavaliangos (2003) and Han et al. (2008). Nevertheless, the variation of deviatoric stress and mean stress $(p=8.8 \mathrm{MPa}$ and $q=9.81$ $\mathrm{MPa}$ ) in the case shown in Figs $2 \& 3$ is lower in this study than previously reported values (Wu et al. (2005), Han et al. (2008)). Hence, the stress state in the current study does not reach the shear failure surface, and no significant dilation due to shear deformation is induced (Train, 1957). Therefore, the density distributions during unloading and ejection are essentially identical and have the similar pattern as observed experimentally for ejected tablets by Train (1957), i.e. the region near the top edges had a greater apparent density while the region near the bottom edge had a lower apparent density, when the powder was compressed with a moving upper punch while the lower punch is kept stationary.

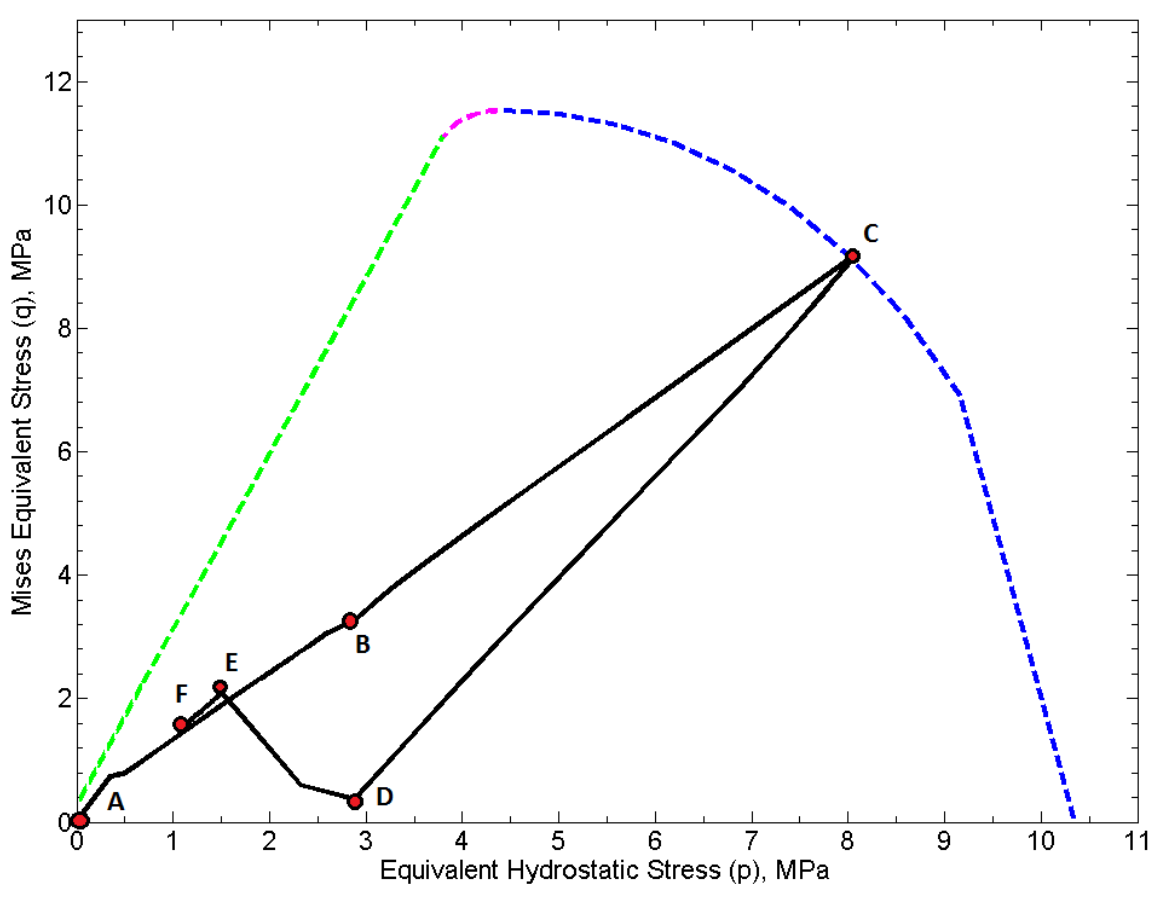

Figure 2 Evolution of the stress state in the p-q plane for making flat-face tablets (friction $\mu=0.3$; compression speed: $12 \mathrm{~mm} / \mathrm{s}$; decompression and ejection speed: $16 \mathrm{~mm} / \mathrm{s})$. 


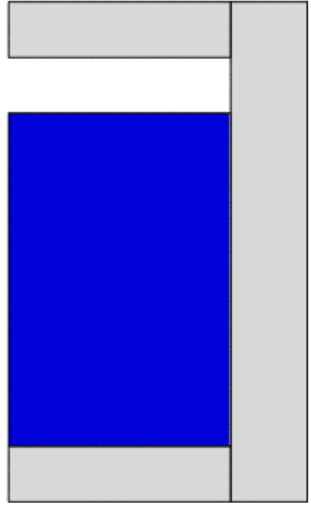

A

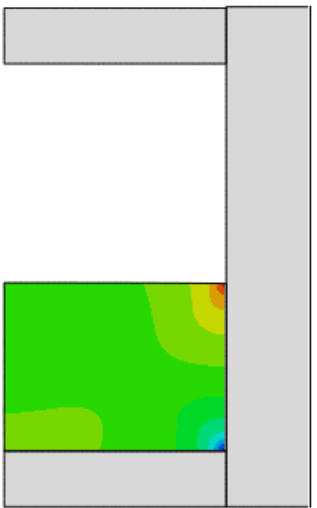

D

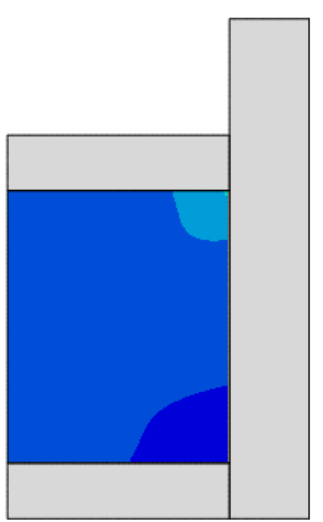

B

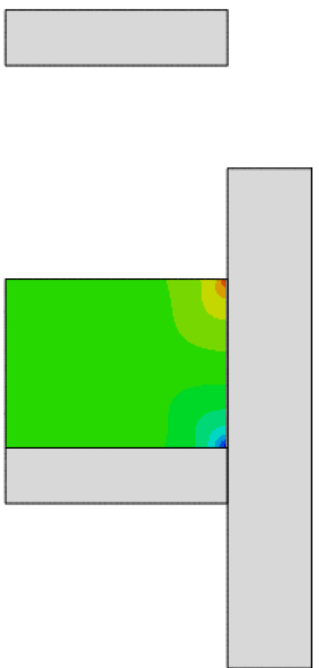

E

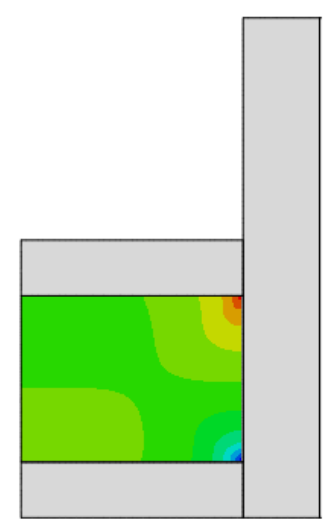

C

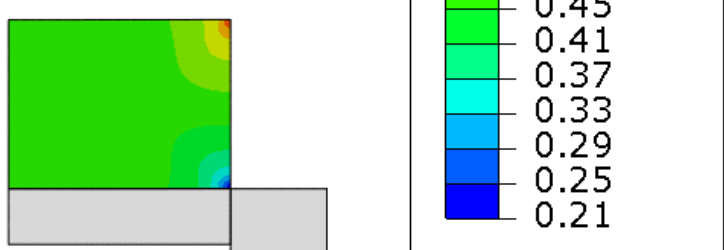

Figure 3 Relative density $(R D)$ distributions at various instants during powder compaction (FF tablets; friction $\mu$ $=0.3$; compression speed: $12 \mathrm{~mm} / \mathrm{s}$; decompression and ejection speed: $16 \mathrm{~mm} / \mathrm{s}$ ).

The corresponding distributions of the local temperature in the powder during compaction are shown in Figure 4. At the beginning of the process the temperature was uniformly distributed in the powder. It can be seen that, during compression, a higher temperature was induced in the vicinity of the upper edge (i.e. near the right upper corner as shown in Figure 4C), which is consistent with the localisation of the highest stress and density in the same location for FF tablets (Michrafy, Ringenbacher, \& Tchoreloff, 2002; Sinka et al., 2003; Krok et al., 2014). Such a distribution is induced from the combined action of wall friction and compression. Moreover, during compression, the temperature increase caused by plastic deformation is more significant than that induced by die wall friction. In addition, some heat at the interface between the powder and the die wall is dissipated through conduction. Consequently, the highest temperature is induced inside the compressed powder rather than at the surface, as shown in Fig. 4C. Furthermore, at the maximum compression (see Fig. 4C), the 
amount of heat generated reaches maximum, as there is no additional external work exerted on the powder. During decompression (unloading, Figure 4D), as the upper punch withdraws, the local temperature inside the tablet decreases. In particular, more significant decrease of temperature is observed in the region close to the die wall, which is attributed to the heat loss by conduction from the powder to the die wall. During unloading, the heat tends to proceed toward the top surface as a result of local heat transfer inside of compacted tablet. During ejection (Figure 4E), the temperature of the powder in the vicinity of the die wall increased due to the effect of die wall friction.

Upon ejection (Figure 4F), a higher temperature is induced at the top surface than that at the bottom surface, which is similar to that observed numerically by Zavaliangos et al. (2007) and Klinzing et al. (2010). This is also in excellent agreement with the experimental observation of Ketolainen et al. (1993), who explored the conversion of thermal energy into mechanical energy during the compaction process of MCC Avicel PH 102 and diCalcium phosphate. These powders were compressed into flat-faced tablets with and without lubricant. And it was observed that the highest temperature was on the upper surface of the tablet and the lowest temperature on the side of the tablet, which was due to heat conduction from powders to the die wall of punch. 


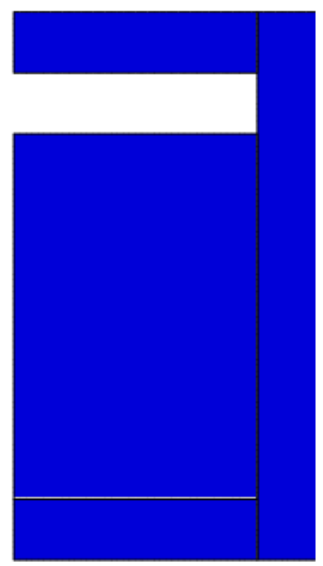

A

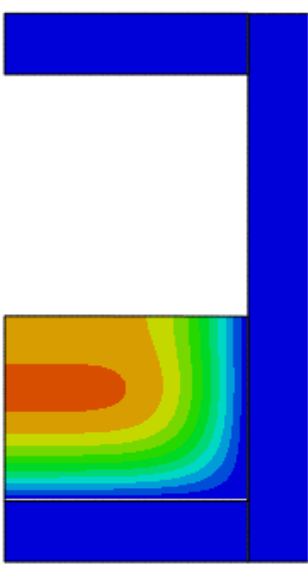

D

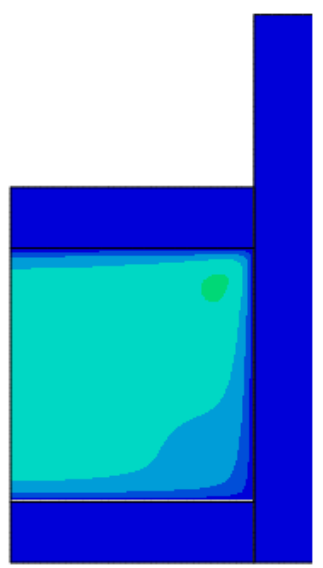

B
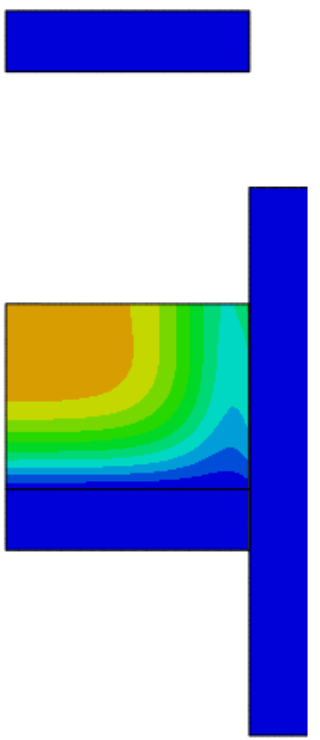

E

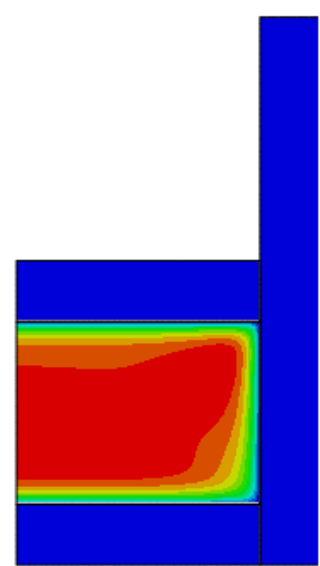

TEMPERATURE

T 35.498

34.373

33.248

32.124

30.999

29.874

28.749

27.624

26.499

25.375

24.250

23.125

22.000

Figure 4 Distributions of local temperature in the powder during powder compaction (FF tablets; friction $\mu=0.3$; compression speed: $12 \mathrm{~mm} / \mathrm{s}$; decompression and ejection speed: $16 \mathrm{~mm} / \mathrm{s}$ ).

The time evolutions of the temperature at six different locations in the powder during compaction are shown in Figure 5. At the point I (top centre) the temperature slightly increases during compression but this temperature increases very sharply during decompression and ejection. The temperatures at points II (centre) rise very quickly during compression, but gradually decrease during decompression and ejection (Fig. 5a). The temperature at the point III (bottom centre) increases slightly during compression and decreases to the temperature $\left(22.5^{\circ} \mathrm{C}\right)$ during decompression and ejection. At points $I V$ (top edge), V (middle edge) \& VI (bottom edge), also the temperature increases slightly at the beginning of compression, but decreases gradually during decompression (Fig. 5b). At ejection, both the radial stresses and the sliding velocity are much lower. Nevertheless, at 
points $I V$ (top edge) \& V (middle edge) it increases sharply during ejection as a consequence of heat generation due to frictional sliding between the tablet and the die wall. It is also interesting to observe that the temperatures at these points (i.e. $I V$ and $V$ ) start to decrease again once the tablet is ejected from the die. A similar pattern is also observed at Point VI (i.e. the bottom edge) but with a much smaller magnitude.

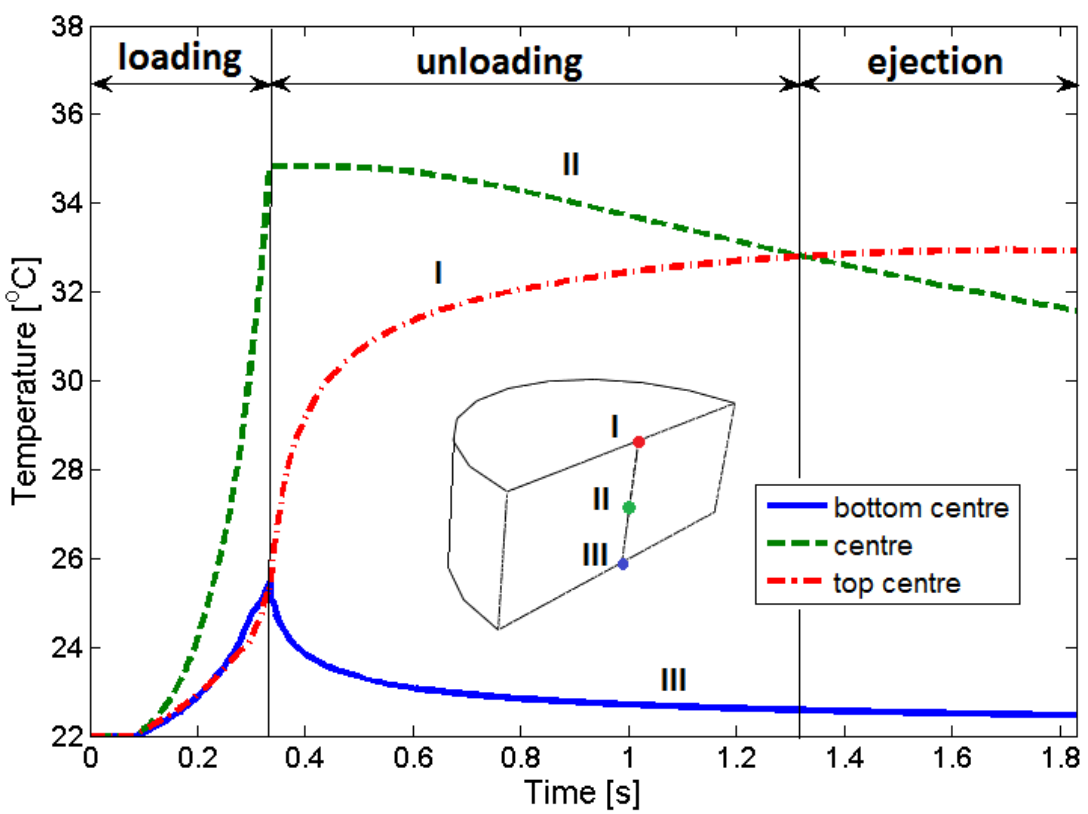

a)

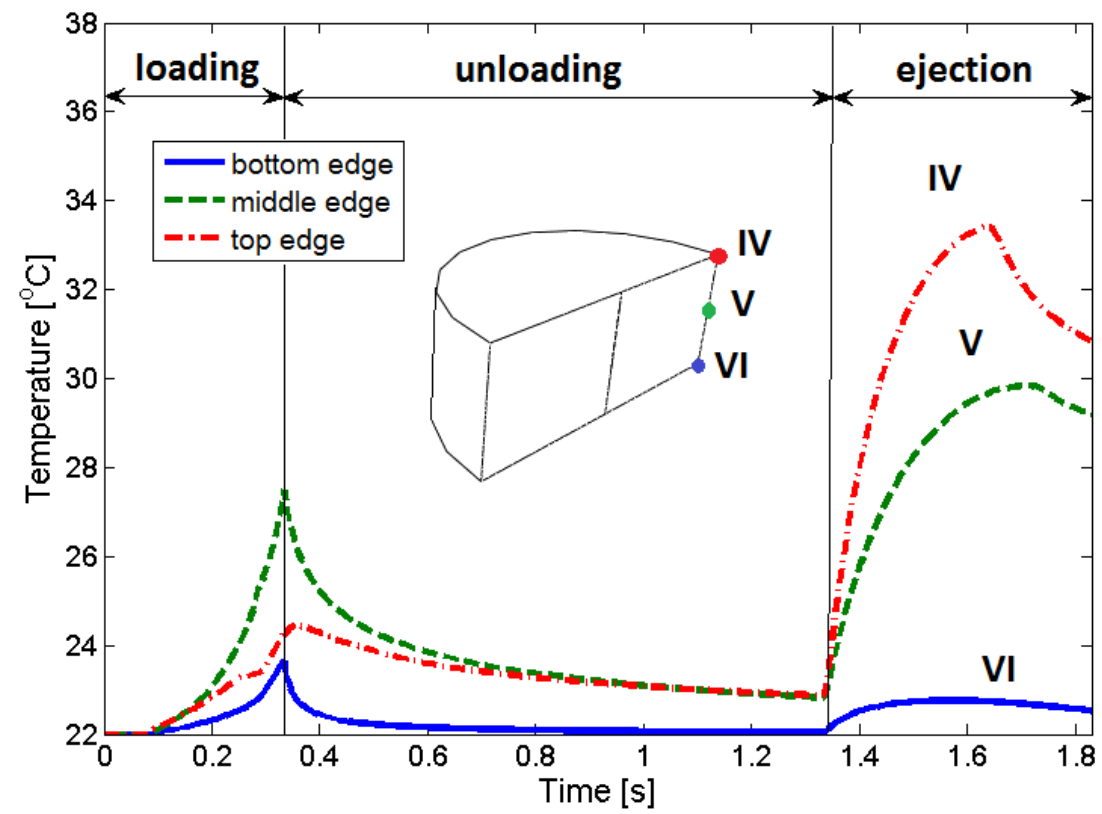

b)

Figure 5 Time evolution of temperature a) at the centre; b) at the edge of the tablet during powder compaction (FF tablets; friction $\mu=0.3$; compression speed: $12 \mathrm{~mm} / \mathrm{s}$; decompression and ejection speed: $16 \mathrm{~mm} / \mathrm{s}$ ). 


\subsection{THE EFFECT OF DIE WALL FRICTION}

The coefficient of friction was chosen in range of $0.1 \sim 0.5$ and initial and boundary conditions for each selected coefficient were preserved. The temperature distributions at the maximum compression with different coefficients of friction are shown in Fig. 6. The results indicate that at a lower friction, an overall lower temperature is induced, implying that the change in the coefficient of wall friction has a significant effect on the generation of heat. This is consistent with the experimental observation of Bechard et al. (1992), who showed that with lubrication (i.e. reducing friction) the temperature dropped from $35^{\circ} \mathrm{C}$ to $29{ }^{\circ} \mathrm{C}$.

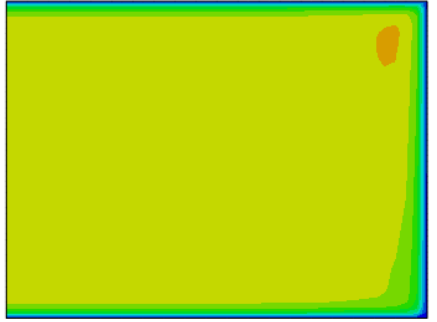

a)

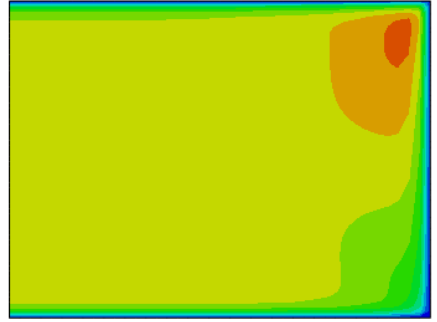

b)
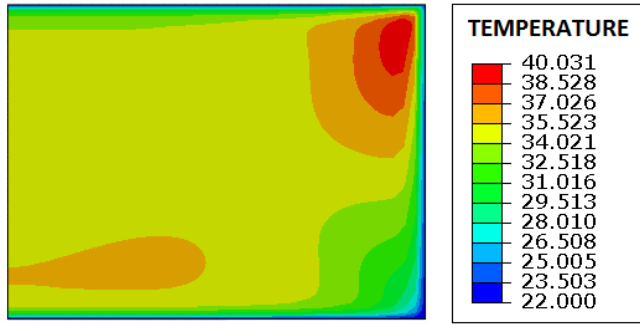

c)

Figure 6 Distribution of temperature in the FF tablet at the maximum compression with wall friction coefficients a) $\mu=0.1$; b) $\mu=0.3$; and c) $\mu=0.5$ (the compression speed is $120 \mathrm{~mm} / \mathrm{s}$ ).

From the temperature distribution shown in Fig. 6, the maximum temperature at any distance from the centre of the tablets in the radial direction can also be obtained and the maximum temperature profiles are shown in Figure 7, in which $\mathrm{x} / \mathrm{R}$ represents the normalized position in the radial direction. It can be seen from Figure 7 that the maximum temperature profiles are also dependent on the friction coefficient, as indicated by Eq. 8. A significant change in temperature occurs mainly near the edge of the tablet (say $\mathrm{x} / \mathrm{R} \sim 0.9$ ) where the temperature drops from $36.1^{\circ} \mathrm{C}$ to $30.8{ }^{\circ} \mathrm{C}$. In this region the heat is generated from both conversion of the mechanical energy and the frictional interaction between the powder and the die wall, i.e. both mechanisms contribute significantly to the heat generation. Thus change in the friction coefficient has a pronounced effect on the maximum pressure in this region. At the edge of the tablet the generated heat was dissipated through conduction into the tooling, so a sharp decrease of the maximum temperature at the tablet edge was observed. Consequently the maximum temperature peaks at some distance away from the edge (e.g. $\mathrm{x} / \mathrm{R} \sim 0.9$ ), especially at high coefficients of friction. It can also be observed that increasing wall friction caused a slight rise in temperature at the edge of the tablet $(\mathrm{x} / \mathrm{R}=1)$, as expected. 
The properties such as the thermal conductivity and the specific heat of the powder can significantly affect the thermomechanical behavior. The thermal conductivity used by Zavaliangos et al., (2007) (i.e. $k_{f}=1.7 \mathrm{~W} / \mathrm{m} / \mathrm{K} ; k_{b}=0.33 \mathrm{~W} / \mathrm{m} / \mathrm{K}$ ), which was higher than the values measured for the powder considered in this study $(k=0.292 \mathrm{~W} / \mathrm{m} / \mathrm{K})$, was also used and the resulted temperature profile was superimposed in Fig.7. It is clear that the behaviour the temperature profiles are similar, however the temperature at the end of compression was higher with a higher value of thermal conductivity.

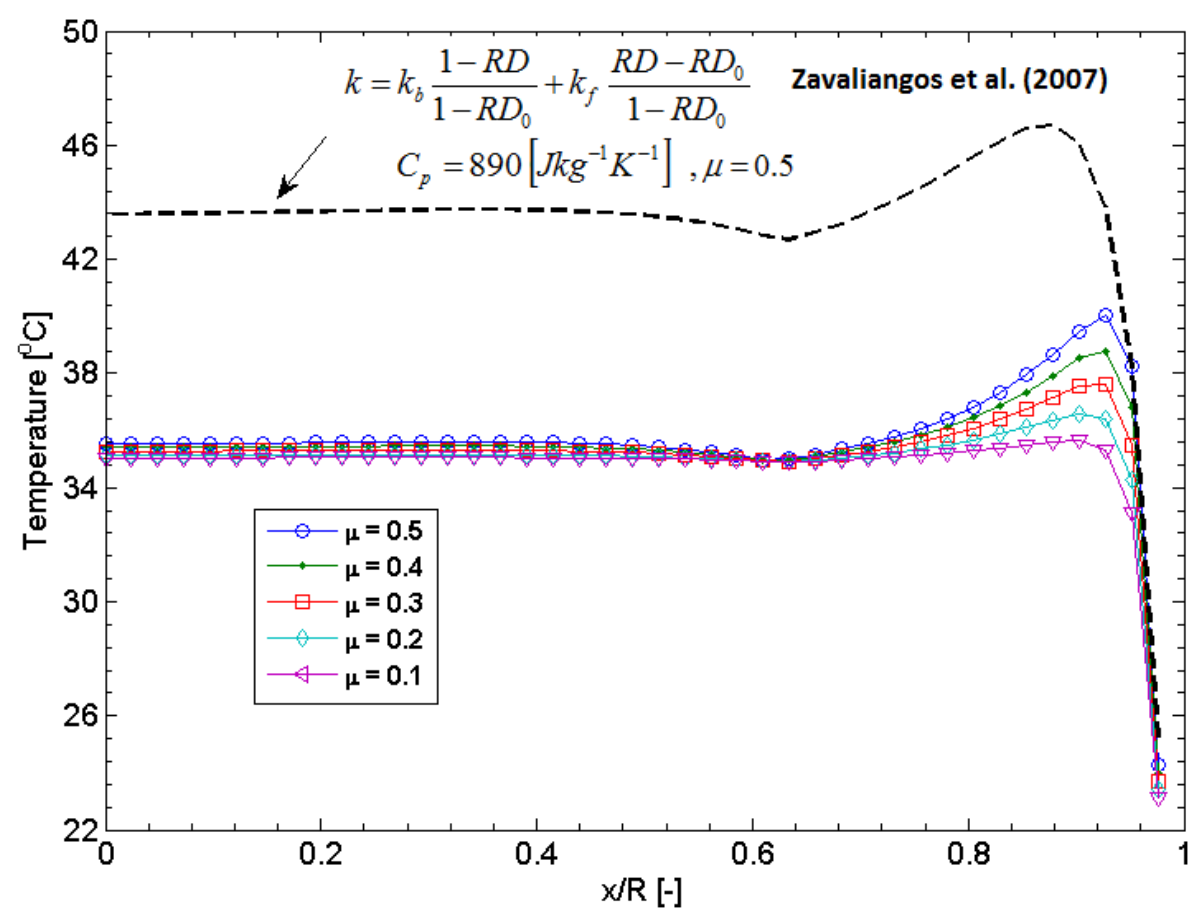

Figure 7 Maximum temperature profile in the FF tablet with wall friction coefficients $\mu=0.1 ; \mu=0.2 ; \mu=0.3 ; \mu$ $=0.4$ and $\mu=0.5$; (compression speed: $120 \mathrm{~mm} / \mathrm{s}$ )

Figure 8 shows the temperature distribution in the tablet after ejection for five different coefficients of wall friction. It is clear that a similar temperature distribution pattern was obtained for the compactions with different coefficients of friction. The highest temperature was induced in the top centre of the tablet, while the lowest temperature at the bottom surface of the tablet. This is attributed to the fact that, as the tablet emerged from the die during ejection, some heat generated in the region close to the tablet edge was dissipated, resulting in a low temperature in this region. Furthermore, the thermomechanical behaviour during ejection was dominated by heat dissipation, so the effect of friction was weakened. The corresponding maximum temperature profiles are presented in see Figure 9. It is clear that after the tablets were ejected, the highest value of the maximum temperature was induced at the centre of the tablet. And the maximum temperature was generally higher for the 
compaction with a greater coefficient of friction, because more heat was generated when the coefficient of friction was higher.

Using the data from Zavaliangos et al. (2007) and Ketolainen et al., (1995), which were independent of the relative density of compacted powder, the temperature profile was also obtained using FEM and superimposed in Figure 9. It can be seen that for $C_{p}=890 \mathrm{~W} / \mathrm{kg} / \mathrm{K}$ used by Zavaliangos et al. (2007), the temperature dropped significantly from $44^{\circ} \mathrm{C}$ to $27.2^{\circ} \mathrm{C}$, but when the specific heat was considered as a function of the relative density as used in this study, the temperature lose was less pronounced.

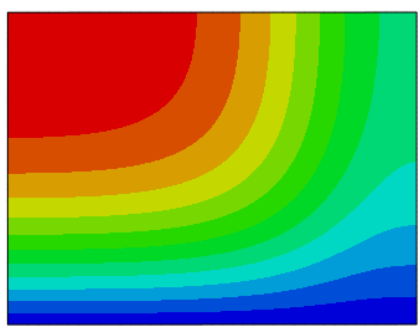

a)

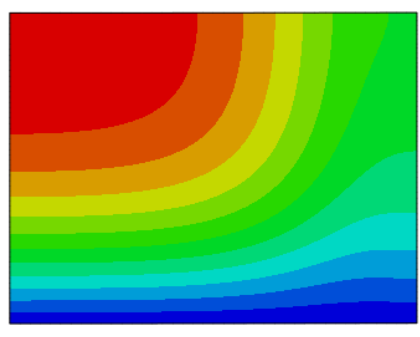

b)
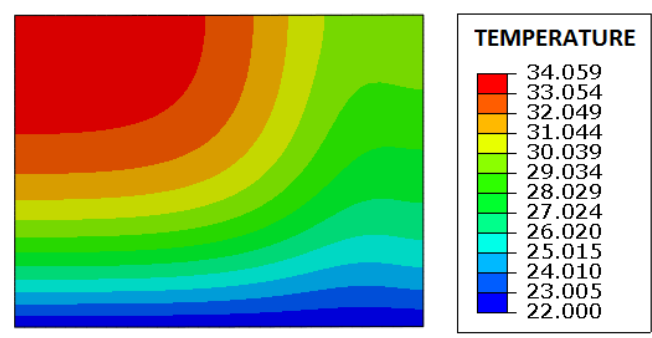

c)

Figure 8 Distribution of temperature in the FF tablet with wall friction coefficients a) $\mu=0.1$; b) $\mu=0.3$; and c) $\mu=0.5$; after ejection $(16 \mathrm{~mm} / \mathrm{s})$.

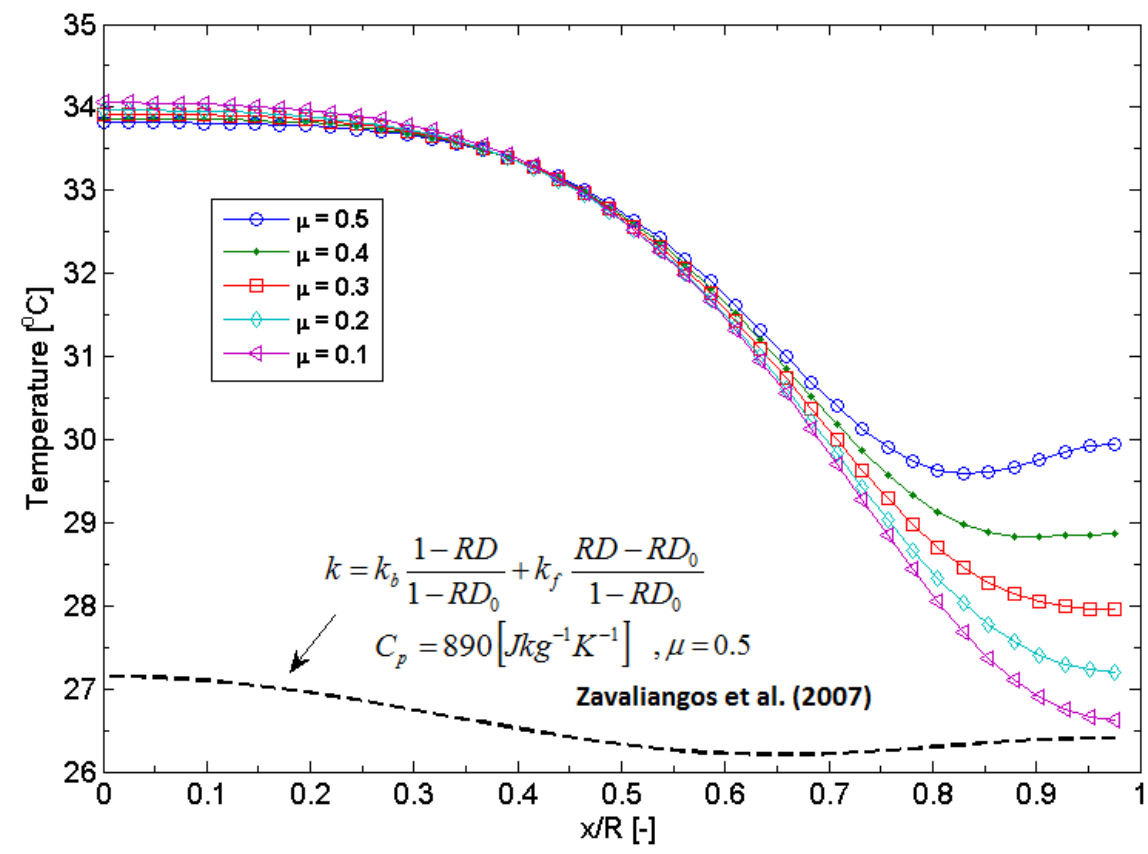

Figure 9 Maximum temperature profile in the FF tablet with wall friction coefficients $\mu=0.1 ; \mu=0.2 ; \mu=0.3 ; \mu$ $=0.4$ and $\mu=0.5$ (ejection speed $=16 \mathrm{~mm} / \mathrm{s}$ ). 


\subsection{THE EFFECT OF COMPRESSION SPEED}

To examine the impact of compression speed on the temperature change, compaction at compression speeds of $12 \mathrm{~mm} / \mathrm{s} ; 120 \mathrm{~mm} / \mathrm{s}$ and $950 \mathrm{~mm} / \mathrm{s}$ were analysed using FEM. In these FEM simulations, the wall friction was kept constant at $\mu=0.5$, the decompression and ejection speeds are assumed at $16 \mathrm{~mm} / \mathrm{s}$. The temperature distributions at the maximum compression at different compression speeds were shown in Fig. 10, and the corresponding maximum temperature profiles were presented in Fig. 11. It is clear from Figs 10 and 11 that the temperature significantly increased when the powder was compressed at a high speed. This was in broad agreement with the experimental observations reported in the literature (Hanus et al., 1968; Bechard et al., 1992). The increase in the compression speed led to an increase in the amount of irreversible work being converted into heat, resulting in an increase in temperature. Furthermore, it also reduced the time for heat transfer to the tooling (i.e. the die wall) during compression, i.e. the amount of heat dissipated was reduced when the compression speed was increased. This is why the highest maximum temperature was induced at the tablet edge rather than the vicinity of the tablet edge observed at low compression speeds, when the compression speed is very high (say $950 \mathrm{~mm} / \mathrm{s}$ ) (see Fig. 11).

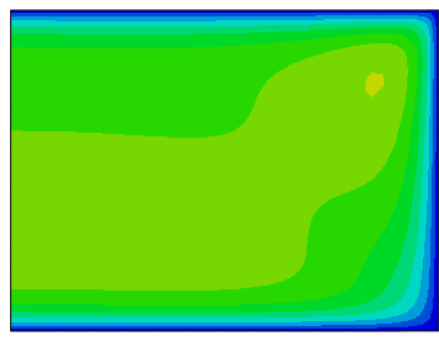

a)

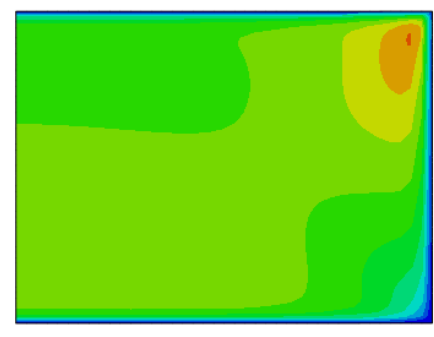

b)
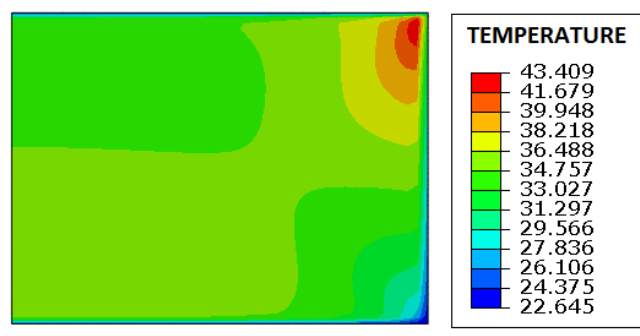

c)

Figure 10 Distribution of temperature in FF tablet for punch speed a) $12 \mathrm{~mm} / \mathrm{s}$; b) $120 \mathrm{~mm} / \mathrm{s}$; and c) $950 \mathrm{~mm} / \mathrm{s}$ with wall friction coefficient $\mu=0.5$ at the maximum compression. 


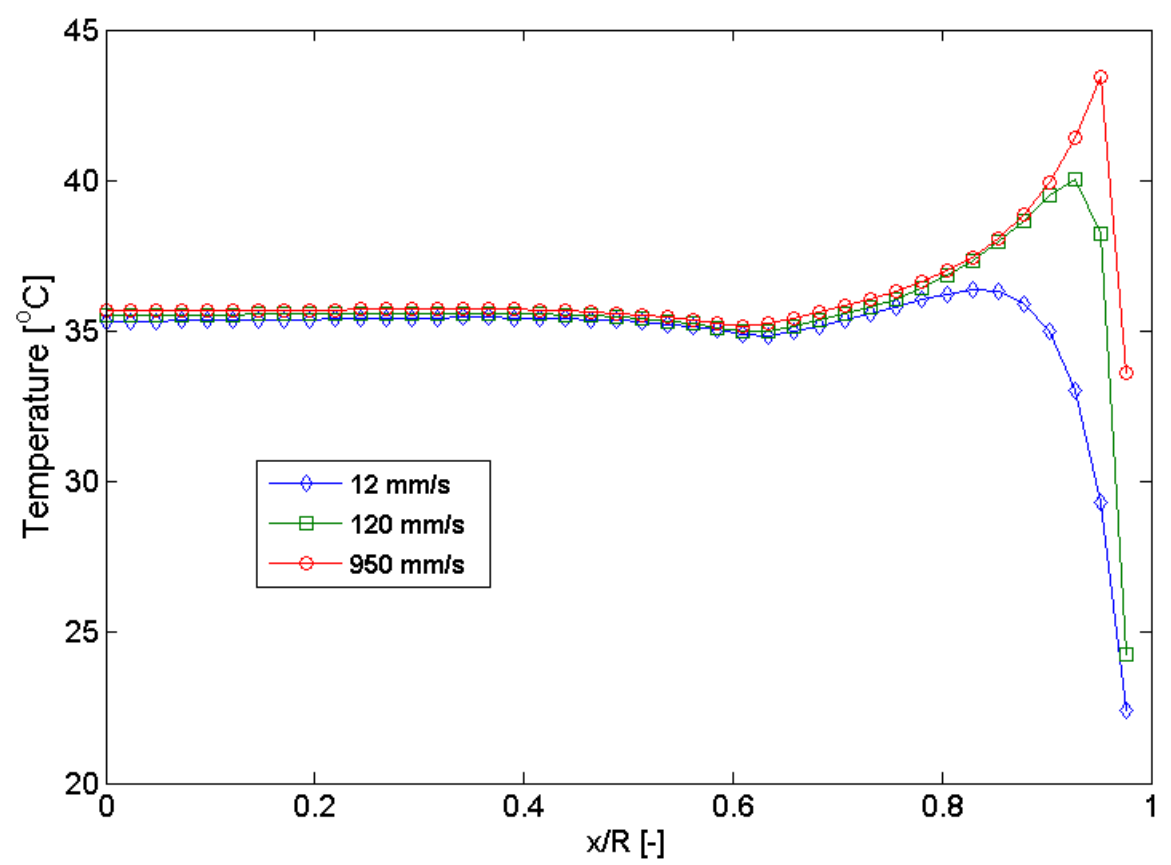

Figure 11 Maximum temperature profile in the FF tablets at the maximum compression produced at various compression speeds with a wall friction coefficient $\mu=0.5$.

The corresponding temperature distributions and the maximum temperature profiles in the ejected FF tablets were presented in Figs 12 and 13, respectively. In all cases, the temperatures at the bottom of the tablet, which remains in contact with the lower punch through the compaction process, is significantly lower than the temperature at the top region of tablet. During unloading and ejection, cooling of the tablet began and the heat tended to be transferred from the warm tablets to die wall and lower punch, i.e. significant heat loss took place through the interfaces between the tablet and the die wall, tablet and the lower punch. Therefore, temperatures in the regions closer to the die wall and lower punch reduced significantly, and the highest temperature was induced at the top centre of the tablet. Furthermore, the higher the compression speed is, the greater the temperature of the ejected tablet.
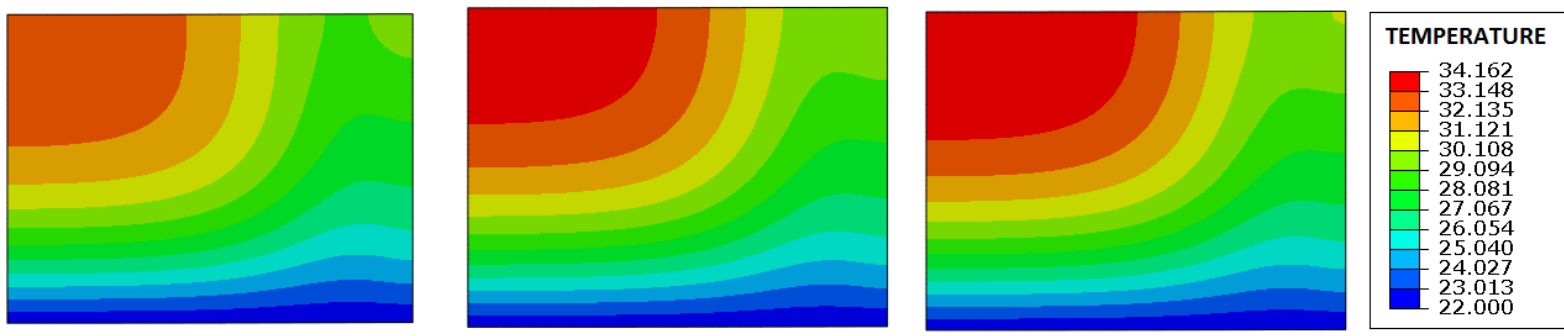

Figure 12 Distributions of temperature of ejected FF tablets with a compression speed of a) $12 \mathrm{~mm} / \mathrm{s}$; b) 120 $\mathrm{mm} / \mathrm{s}$; and c) $950 \mathrm{~mm} / \mathrm{s}$ with wall friction coefficient $\mu=0.5$. 


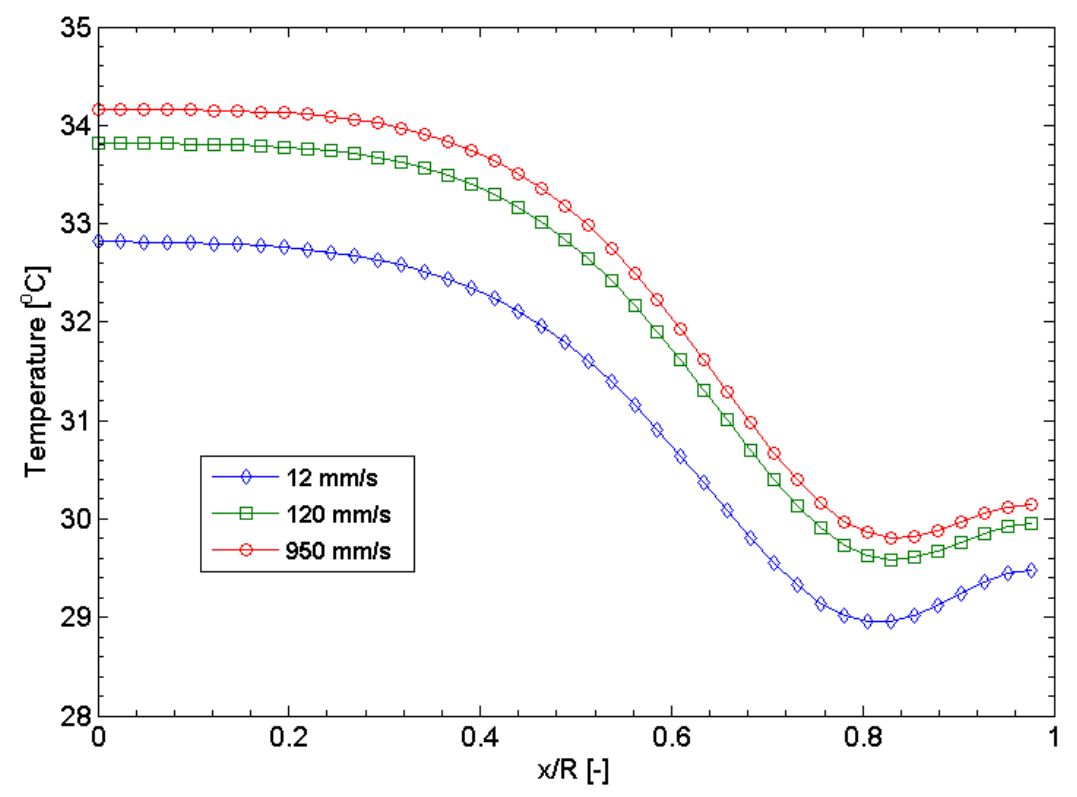

Figure 13 Maximum temperature profile in the FF tablets after ejection produced at various compression speeds with a wall friction coefficient $\mu=0.5$.

\subsection{THE EFFECT OF PUNCH SHAPE}

Thermo-mechanical behaviours during compaction with various punch shapes were also investigated, as shown in Fig. 1. For all cases consider here, the thickness of the final tablets was kept at $2 \mathrm{~mm}$, the compression speed was set at $120 \mathrm{~mm} / \mathrm{s}$, while the speeds of decompression and eject were $16 \mathrm{~mm} / \mathrm{s}$. A wall friction of $\mu=0.5$ was chosen.

The temperature distributions inside the FF, SC, STC tablets at the maximum compression were shown in Figure 14. It can be seen from this figure that the shape of the punch had a great impact on the temperature of the compressed powder. As the curvature radius of the punch decreased, higher temperature was induced. That is to say, a much higher temperature was induced when a curved punch was used to produce STC tablets, than other two cases. This is because the degree of deformation for making the STC tablet was the highest as the initial powder bed was compressed into a much smaller volume. This implies that the irreversible amount of work increased, so a greater amount of heat was generated in the tablet, as the curvature radius decreased.

The temperature distributions in various shaped tablets after ejection were shown in Fig. 15, similar to the discussion in $\S 4.3$, the temperature in the region closer to the lower punch was lower than that at the upper region of the tablets, because more heat was lost by conduction 
into the lower punch. Some heat also dissipated through the contact between powder bed and the die wall during ejection. Thus the temperature in the region close to the die wall was low, while the highest temperature was induced at the top centre. Moreover, the temperature in the ejected STC tablet was also the highest one.

The maximum temperatures in the ejected tablets of various shapes with various coefficients of friction were obtained to explore the combined effect of punch shape and die wall friction. The results were shown in Fig. 16. It can be seen that the maximum temperature generally increase as the die wall friction increases but at a very low rate. However, when the punch shape was changed from FF to SC and STC, the maximum temperature increased dramatically. This implies that the degree of deformation (by varying the punch shape) had a more significant effect on the temperature rise in the tablets than the die wall friction. In other word, reducing die wall friction by using lubricants can reduce the maximum temperature induced during tabletting process, but also to a very small degree.

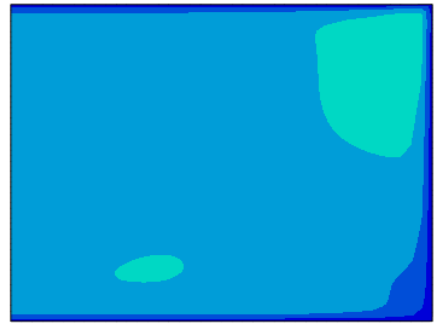

a)

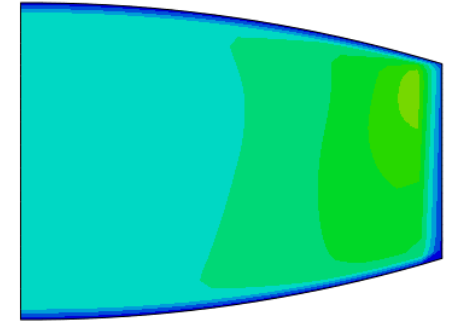

b)

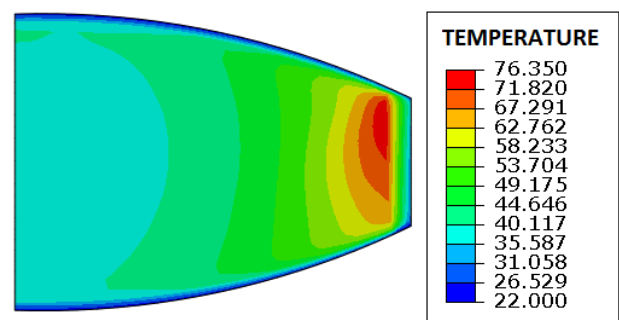

c)

Figure 14 Distribution of temperature at the maximum compression in a) a FF tablet; b) SC tablet and c) STC tablet (compression speed: $120 \mathrm{~mm} / \mathrm{s} ; \mu=0.5$ )

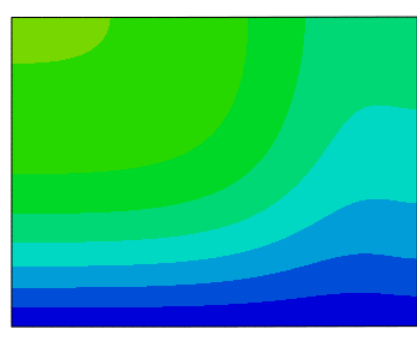

a)

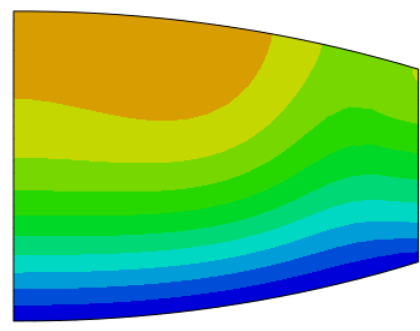

b)
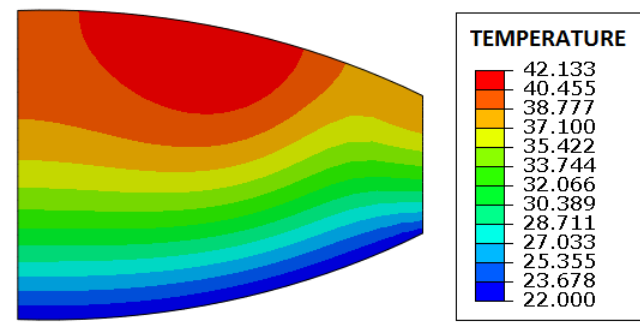

c)

Figure 15 Distributions of temperature in a) a FF tablet; b) SC tablet and c) STC tablet after ejection (ejection speed: $16 \mathrm{~mm} / \mathrm{s} ; \mu=0.5$ ) 


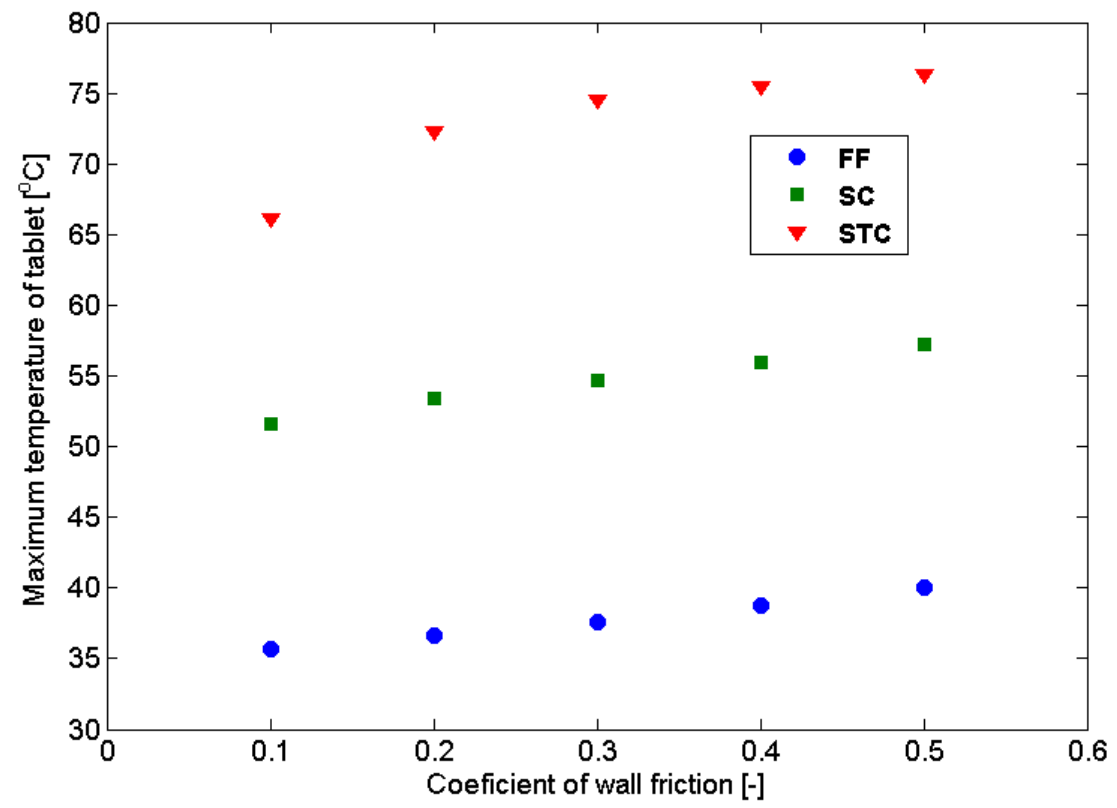

Figure 16 The effect of wall friction coefficient on maximum temperature in FF, SC and STC tablets (compression speed: $120 \mathrm{~mm} / \mathrm{s}$ )

\section{CONCLUSIONS}

Finite element modelling of tabletting was performed to explore the effect of wall friction, compression speed and punch shape on the thermo-mechanical behaviour of the MCC powder. It was found that, for making flat faced tablets, the numerical results are in broad agreement with experimental and numerical observations reported in the literature. It was shown that as the compression speed increases, the amount of irreversible work increases. Consequently, more heat is generated and a higher temperature is induced. When the die wall friction coefficient $(\mu)$ increases, higher shear stress at the powder-tooling interface is induced, as a result, a higher temperature is induced. When the radius of the surface curvature decreases (FF>SC $>$ STC), overall degree of powder deformation increases. Consequently the highest temperature is induced in the STC tablets. It was noticed that the degree of deformation in tableting has a more dominant impact on the temperature rise than the die wall friction.

\section{ACKNOWLEDGMENTS}

This work was supported by the Marie Curie Intra-European Fellowships, funded through the People Programme (Marie Curie Actions) of the European Union's Seventh FP7 under REA grant agreement No. 622874 (acronym: ThermoPC). We thanks Nuno Vitorino for assistance in the thermal properties measurement. 


\section{LIST OF SYMBOLS}

A

Interacting area

$\left[\mathrm{m}^{2}\right]$

$C_{p}$

Specific heat

$\left[\mathrm{J} . \mathrm{kg}^{-1} \cdot \mathrm{K}^{-1}\right]$

E

Young's modulus

[Pa]

F

Plastic flow potencial

[Pa]

H

Initial height

[m]

I

Identity matrix

$[-]$

$R_{E}$

Cap eccentricity

$[-]$

$R$

Radius of the tablet

[m]

$R D$

Relative density

$[-]$

$R D_{0}$

bulk relative density

$[-]$

$S$

Tensor of deviator stress

$[\mathrm{Pa}]$

Temperature

[K]

Cohesion

$[\mathrm{Pa}]$

Thermal conductivity

$\left[\mathrm{W} \cdot \mathrm{m}^{-1} \cdot \mathrm{K}^{-1}\right]$

Thermal conductivity of full

$\left[\mathrm{W} \cdot \mathrm{m}^{-1} \cdot \mathrm{K}^{-1}\right]$

dense material

Thermal conductivity of loose

$\left[\mathrm{W} \cdot \mathrm{m}^{-1} \cdot \mathrm{K}^{-1}\right]$

powder

Thermal conductivity of

$\left[\mathrm{W} \cdot \mathrm{m}^{-1} \cdot \mathrm{K}^{-1}\right]$

powder

$k_{\prime \prime}$

Thermal conductivity of tool

$\left[\mathrm{W} \cdot \mathrm{m}^{-1} \cdot \mathrm{K}^{-1}\right]$

steel

Hydrostatic stress

[Pa]

Evolution paramer

[Pa]

Hydrostatic Yield stress

[Pa]

$q$

Mises equivalent stress

[Pa] 


\begin{tabular}{|c|c|c|}
\hline$\dot{q}_{p}$ & Total heat source & {$[\mathrm{W}]$} \\
\hline$\dot{q}_{\phi}$ & $\begin{array}{l}\text { Rate of internal heat } \\
\text { generation due to internal } \\
\text { friction }\end{array}$ & {$\left[\mathrm{W} \cdot \mathrm{m}^{-3}\right]$} \\
\hline$\dot{q}_{\omega}$ & $\begin{array}{l}\text { Rate of external heat } \\
\text { generation due to wall friction }\end{array}$ & {$\left[\mathrm{W} \cdot \mathrm{m}^{-2}\right]$} \\
\hline$\dot{q}_{I}$ & $\begin{array}{l}\text { Rate of external heat } \\
\text { generation due to wall friction } \\
\text { to the powder }\end{array}$ & {$\left[\mathrm{W} \cdot \mathrm{m}^{-2}\right]$} \\
\hline$\dot{q}_{I I}$ & $\begin{array}{l}\text { Rate of external heat } \\
\text { generation due to wall friction } \\
\text { to the die tools }\end{array}$ & {$\left[\mathrm{W} \cdot \mathrm{m}^{-2}\right]$} \\
\hline$u$ & Norm of the local slip velocity & {$\left[\mathrm{ms}^{-1}\right]$} \\
\hline$\alpha$ & Coefficient of transition curve & {$[-]$} \\
\hline$\alpha_{\mathrm{T}}$ & Thermal expansion coefficient & {$\left[K^{-1}\right]$} \\
\hline$\beta$ & Internal friction angle & {$\left[{ }^{\circ}\right]$} \\
\hline $\boldsymbol{\sigma}$ & Stress tensor & {$[\mathrm{Pa}]$} \\
\hline$\sigma_{\mathrm{nn}}$ & Local normal stress & {$[\mathrm{Pa}]$} \\
\hline$\rho$ & Local density & {$\left[\mathrm{kg} \cdot \mathrm{m}^{-3}\right]$} \\
\hline$\varepsilon_{\mathrm{v}}$ & Volume plastic strain increment & {$[-]$} \\
\hline$\eta$ & Weighting factor & {$[-]$} \\
\hline$v$ & Poisson ratio & {$[-]$} \\
\hline$\lambda$ & Thermal diffusivity & {$\left[\mathrm{m}^{2} \mathrm{~s}^{-1}\right]$} \\
\hline$\lambda_{1}$ & Thermal diffusivity of powder & {$\left[\mathrm{m}^{2} \mathrm{~s}^{-1}\right]$} \\
\hline$\lambda_{\|}$ & Thermal diffusivity of tool steel & {$\left[\mathrm{m}^{2} \mathrm{~s}^{-1}\right]$} \\
\hline$\mu$ & Wall friction coeficient & {$[-]$} \\
\hline$\xi$ & Inelastic heat fration & {$[-]$} \\
\hline
\end{tabular}

\section{REFERENCES}


Arrifn, A. K., Rahman, M. M., Jumahat, A. (2003). An Experimental investigation of warm poder compaction process, in: BSME-ASME International Conference on Thermal Engineering, Dhaka, January

Arruda, E. M., Boyce , M. C., Jayachandran, R. (1995). Effects of strain rate, temperature and thermomechanical coupling on the finite strain deformation of glassy polymers, Mech Mater, 19, pp. 193-212

Bechard, S. R., Down, G. R. B. (1992). Infrared imaging of pharmaceutical materials undergoing compaction, Pharm Res, 9, pp.521-528

Brevin, P. R., Coube, O., Doremus, P., Tweed, J. H. (2008). Modelling of powder die compaction, New York: Springer.

Bever, M. B., Holt, D. L., Titchener, A. L. (1973). The stored energy of cold work, In: Chalmers, B., Christian, J. W., Massalski, T. B., editors. Progress in Materials Science, 17, pp. 5-88

Cespi, M., Bonacucina, G., Casettari, L., Ronchi, S., Palmieri, G. F. (2013). Effect of temperature increase during the tableting of pharmaceutical materials, International Journal of Pharmaceutics, 448, pp. 320-326

Cunningham, J. C., Sinka, I. C., Zavaliangos, A. (2004). Analysis of Tablet Compaction. I. Characterization of Mechanical Behaviour of Powder and Powder/Tooling Friction, Journal of Pharmaceutical Sciences, 93, pp. 2022-2039

Diarra, H., Mazel, V., Busignies, V., Tchoreloff, P. (2013). FEM simulation of the die compaction of pharmaceutical products: Influence of visco-elastic phenomena and comparison with experiments, International Journal of Pharmaceutics, 453, pp. 339-394

Grzesik, W. (2008). Advanced Machining Processes of Metalic Materials, Elsevier Science

Han, L. H., Elliott, J. A., Bentham, A. C., Mills, A., Amidon, G. E., Hancock, B. C. (2008). A modified Drucker-Prager Cap model for die compaction simulation of pharmaceutical powders, International Journal of Solids and Structures, 45, pp. 3088-3106

Hanus, E. J., King, L. D. (1968). Thermodynamic effects in the compression of solids, Journal of Pharmaceutical Sciences, 57, pp.677-684

Kadiri, M. S., Michrafy, A. (2013). The effect of punch's shape on die compaction of pharmaceutical powders, Powder Technology, 239, pp. 467-477

Kaschnitz, E., Hofer, P., Funk, W. (2012). Thermophysical Properties of a Hot-Work ToolSteel with High Thermal Conductivity, International Journal of Thermophysics, 34, pp. $843-850$

Ketolainen, J., Ilkka, J., Paronen, P. (1993). Temperature changes during tableting measured using infrared thermoviewer, International Journal of Pharmaceutics, 92, pp.157-166 
Ketolainen, J., Kubičak, L', Boháč, V., Markovič, Paronen, P. (1995). Thermophysical Properties of Some Pharmaceutical Excipients Compressed in Tablets, 12, pp. 1701-1707

Klinzing, G. R., Zavaliangos, A., Cunningham, J., Macaro, T., Winstead, D. (2010). Temperature and density evolution during compaction of a capsule shaped tablet, Computers and Chemical Engineering, 34, pp.1082-1091

Krok, A., Peciar, M., Fekete, R. (2014). Numerical investigation into the influence of the punch shape on the mechanical behaviour of pharmaceutical powders during compaction, Particuology, 16, pp. 116-131

Mazor, A., Perez-Gandarillas, L., de Ryck, A., Michrafy, A. (2016). Effect of roll compactor sealing system designs: A finite element analysis, Powder Technology, 289, pp. 21-30

Michrafy, A., Haas, S., Kadiri, M., Sommer, K., Dodds, J. (2006). The effects of ambient temperature on the compaction of pharmaceutical powders, Proc I MECH E Part E J Process Mech Eng 220, pp.1-6

Michrafy, A., Ringenbacher, D., Tchoreloff, P. (2002). Modelling the compaction behaviour of powders: application to pharmaceutical powders, Powder Technology, 127, pp. 257-266

Muliadi, A. R., Litster, J. D., Wassgren, C. R. (2013). Validation of 3-D element analysis for predicting the density distribution of roll compacted pharmaceutical powder, Powder Technology, 237, Pages 386-399

Nürnberg, E., Hopp, A. (1981). Temperature measurement during tableting, Pharm. Technology, 168, pp.81-101

Procopio, A. T., Zavaliangos, A., Cunningham, J. C. (2003). Analysis of the diametrical compression test and the applicability to plastically deforming materials. Journal of Materials Science, 38, pp. 3629-3639

Rahman, M. M., Ariffin, A. K., Nor, S. S. M. (2009). Development of a finite element model of metal powder compaction process at elevated temperature, Applied Mathematical Modelling, 33, pp. 4031-4048

Reznikov, A. N. (1981). Thermophysical Aspects of Metal Cutting Processes (In Russian), Mashinostroenie, Moscow, (1981)

Roue'che, E., Serris, E., Thomas, G., Périer-Camby, L. (2006). Influence of temperature on the compaction of an organic powder and the mechanical strength of tablets, Powder Technology, 162, pp. 138-144

Sinha, T., Curtis, J. S., B. C. Hancock, B. C., Wassgren, C. (2010). A study on the sensitivity of Drucker-Prager Cap model parameters during the decompression phase of powder compaction simulations, Powder Technology, 198, pp. 315-324

Sinka, C., Cocks, A. C. F.: "Modelling Die Compaction in the Pharmaceutical Industry", in Brewin, P. R., Coube, O. , Doremus, P., Tweed, J. H., Editors, Modelling of Powder Die Compaction, Springer-Verlag, London, 2008 
Sinka, I. C., Cunningham, J. C., Zavaliangos, A. (2003). The effect of wall friction in the compation of pharmaceutical tablets with curved faces: a validation study of the DruckerPrager Cap model, Powder Technology, 133, pp. 33-43

Travers, D. N., Merriman, M. P. (1970). Temperature changes occurring during the compression and recompression of solids, Journal of Pharmacy and Pharmacology, 22, pp.11S-16S

Train, D. (1957). Transmission of forces through a powder mass during the process of pelleting. Transactions of the Institution of Chemical Engineers, 35, pp. 258-266

Wu, C.Y., Ruddy, O.M., Bentham, A.C., Hancock, B.C., Best, S.M., Elliott, J.A. (2005). Modelling the mechanical behaviour of pharmaceutical powders during compaction, Powder Technology, 152, pp. 107-117

Wu, C.Y., Hung, W.L., Miguélez-Morán, A. M., Gururajan, B., Seville. J.P.K. (2010). Roller compaction of moist pharmaceutical powders. International Journal of Pharmaceutics, 391, pp. $90-97$

Zavaliangos, A., Galen, S., Cunningham, J., Winstead, D. (2007). Temperature evolution during compaction of pharmaceutical powders, Journal of Pharmaceutical Sciences, 97, pp. 3291-3304

Zhang, G. G. Z., Law, D., Schmitt, E. A., Qiu, Y. (2004). Phase transformation considerations during process development and manufacture of solid oral dosage forms. Advanced Drug Delivery Reviews, 56(3), pp. 371-390 